\title{
Energy: A Concept Analysis
}

Rashondra Calderon ${ }^{1}$, Kelsey Cooper ${ }^{1}$ and Sharon L. Van Sell ${ }^{2}$

${ }^{1}$ Graduate Nursing Program, Texas Woman's University, USA

${ }^{2}$ Professor, The Houston J. and Florence A. Doswell College of Nursing, Texas Woman's University, USA

\begin{abstract}
The concept of energy can be very important and somewhat abstract regarding nursing in its entirety. Energy constituted one way to connect with the environment, other individuals, and learning to interconnect those findings within the advanced practitioner nurse (APN) role. The concept of energy was analyzed using the Walker and Avant eight-step methodology to assist APNs to gain a diverse perspective of how energy can be used in practice. The attributes of the concept of energy included aperson, aura, movement, and current. The antecedents provided were God and life. From the perspective of energy, all energy must have come from something greater than human beings. Model cases provided for a unique comparison of what energy is and what energy is not, and how to interpret the concept of energy.
\end{abstract}

\section{Publication History:}

Received: January 27, 2017

Accepted: April 04, 2017

Published: April 06, 2017

\section{Keywords:}

Energy, Exchange, Interconnected, God, Advanced practice nurse, Touch

\section{Introduction}

How has energy been defined? The concept of energy has evolved over time and across disciplines. Different meanings of the word energy appeared in physics, philosophy, nursing, biology, medicine, and cosmology [1]. Some disciplines have viewed energy as various forms of matter; others, as an electrical field that can be manipulated to promote healing among patients.

How does the concept of energy apply to the advanced practice nurse (APN)? According to Walker and Avant [2], "concept analysis can be useful in refining ambiguous concepts in a theory" (p. 158). Some theorists in nursing and other fields have formulated theories and concepts to better understand the concept of energy and the implications of energy on nursing practice and in other disciplines. The authors of the present concept analysis refined the concept, statements, and theories of the concept energy related to the application in APN practice.

\section{Concept Analysis}

\section{Aim of the concept analysis}

Concept analysis promoted understanding of the topic. According to Walker and Avant [2], not only can concept analysis be "useful in refining ambiguous concepts in a theory," but "it also helps clarify those overused or vague concepts that are prevalent in nursing practice so that everyone who subsequently uses the term will be speaking of the same thing" (p.158). Walker and Avant [2] proposed an eight-step process for concept analysis, starting with identifying the concept to be analyzed.

The next step in the process of concept analysis was to determine the aim or purpose. The aim identified why the concept of energy was important and how the results of the concept analysis applied to advanced practice nursing. The confounding problem was that energy is a concept used across many disciplines such as science, philosophy, and physics with different definitions and applicability. The purpose of the concept analysis was to define the concept of energy related to the APN. The goal was to explore the belief that energy fields can positively or negatively influence the energy fields of others. Understanding the relationship between the energy fields was deemed crucial for the APN in the provision of holistic care.

\section{Relating Theory to Practice}

"Theories that are useful in nursing practice describe phenomena, explain how things work, predict results, prescribe interventions or therapies" (p. 40) [2]. Theories have guided nursing practice. Unfortunately, the concept of energy was relatively new to the nursing practice; with the very limited applicability of energy to the APN. Several theories, however, have defined and discussed the energy exchange between the nurse, human being, and environment. For example, Van Sell and Kalofissudis' [3] complexity integration nursing theory (CINT) and Myra Levine's [5] conservation theory provided insight into the use of energy in nursing practice.

CINT described the human being as an open, complex system who interacted with the environment to evolve into a dynamic entity [3]. Energy and matter comprised the human being. The energy exchanged between the human being, and the environment was constant. Similar to the human being in Martha Rogers' [5] Theory, Van Sell and Kalofissudis [3] described the human being as a pattern of organization continuously influx with matter to reach higher cognitive function. Energy exchange occurred between the human being and the nurse when the nurse cared for the human being. Van Sell and Kalofissudis [3] observed, "The transformed energy flourishes as the nurse as an individual human being, flourishes the nurse's social group, and continues into the social entirety" (p. 68).The nurse aided the human being in maintaining the flow of energy to sustain life through nursing care and interventions. CINT applied to APNs in a similar way in that APNs must maintain a continuous flow of energy among themselves, their patients, and the universe. When the APN's energy flow was disturbed, the disturbance inhibited the APNs ability to diagnose, treat, and interact with patients.

Levine's [4] theory focused on conservation. The theory emphasized the importance of maintaining a balance between the nurse and the

"Corresponding Author: Prof. Sharon L. Van Sell, The Houston J. and Florence A. Doswell College of Nursing, 5500 Southwestern Medical Avenue, \#7209, Dallas, Texas, USA, 75235-7299, Tel: 1-864-275-3527, FAX: 214-689-6539; E-mail: svansell@twu.edu

Citation: Calderon R, Cooper K,Van Sell SL (2017) Energy: A Concept Analysis. Int J Nurs Clin Pract 4: 230. doi: https://doi.org/10.15344/2394-4978/2017/230

Copyright: (c) 2017 Calderon et al. This is an open-access article distributed under the terms of the Creative Commons Attribution License, which permits unrestricted use, distribution, and reproduction in any medium, provided the original author and source are credited. 
patient. According to Levine [4], conservation occurred across time and space continuum, and nurses adapted their interventions to meet the patient's changing needs. Nursing care focused on the patient's interaction with his or her internal and external environment. Levine's principle of conservation of patient energy focused on the nurses conserving the patient's energy. The ability of the nurse to conserve the patient's energy protected the patient from disease. In addition, nurses adapted their care to ensure the patient's energy expenditure did not exceed the patient's energy reserve. In turn, APNs must conserve their own energy to carry out their designated responsibilities. Further, APNs must be consciously aware of their energy expenditure and need to maintain a balance between interacting with their patients and their environment. When the balance was disturbed, for example when the APNs got sick, the APN were unable to provide holistic care.

\section{Definitions and uses of energy}

The concept of energy had many different meanings across disciplines and depended on the context in which energy was discussed. Defining the word was, therefore, important to fully grasp the true meaning of the concept of energy. For example, the Merriam-Webster Online Dictionary [6] defined energyas "the ability to be active: the physical or mental strength that lets you do things" (para. 1), "natural enthusiasm and effort" (para. 2), or "usable power that comes from heat, electricity, etc." (para. 3).In Dictionary.com [7], energy in medicine was "the capacity for work or vigorous activity; vigor; power" (para. 1) or "the capacity of a physical system to do work" (para. 2); in contrast, energy in science was "the capacity or power to do work, such as the capacity to move an object (of a given mass) by the application of force" (para. 1). Energy in physics was "the ability to do work" [7]. According to the Cambridge Dictionary [8], energy related to strength as "the power and ability to be physically and mentally active" (para. 1), while energy related to power was the "power to do work that produces light, heat, motion, or the fuel or electricity used for power" (para. 1). Finally, the Business Dictionary [9] defined energy as follows:

A measure of the ability of a body or system to do work or produce a change expressed usually in joules or kilowatt hours (kWh). No activity is possible without energy, and its total amount in the universe is fixed. In other words, it cannot be created or destroyed but can only be changed from one type to another.

The authors of the present concept analysis conducted an integrated literature review to further define the concept of energy and energy's application across various fields. The databases used to research the concept of energy included Cumulative Index to Nursing and Allied Health Literature (CINAHL), PubMed, and Academic Search Complete. The authors found 40 articles related to the concept of energy, but only eight references aided in further defining the word energy.

The first discussion of energy came from the science of physics. Physicist Sir Isaac Newton [10] described three laws of motion, believing particles within the body created forces that are either attracted to or repel each other. The forces of a given body, according to Newton [10], were influenced by gravity, motion, and density. The third law of motion declared, "to every action, there is always opposed an equal reaction: or the mutual actions of two bodies upon each other are equal, and directed to contrary parts" (p. 83) [10]. Newton's third law of motion indicated a force applied to a body could change the motion of that body in a direction away from the force; alternatively, the body can be attracted to the force. The laws of motion developed by Newton were said to be the beginning point for the description of energy [1].

Mathematician and physicist Albert Einstein developed the theory of relativity to describe energy and matter [11]. According to Einstein and Infeld, no distinction existed between mass and energy; in fact, mass made up energy. The theory of relativity identified energy as having weight as a result of small particles of matter making up mass. An exchange occurred between mass and matter.

Theories have evolved from the concept of energy not only in the field of physics but also in nursing science. Rogers [5], a well-known nurse theorist, developed the theory called the science of unitary human beings that discussed the whole of the human being to include physical, biological, psychological, social, cultural, and spiritual attributes. The attributes were not distinguished from one another but connected to each other in a complex way. According to Rogers, the human being consisted of an energy field. The energy field provided a conceptual boundary of the human being and identified the human being as a whole entity. Rogers described the energy field as the basic unit of human behavior, and the energy field consisted of pattern and organization. Rogers defined the human being as an open, dynamic system continuously interacting with the environment. The energy fields of the human being and environment exchanged matter and energy. The interaction between the energy fields fluctuated depending on the given space and time of a situation. The fluctuation allowed the human being's energy field to evolve and grow in complexity. The change that occurred between the whole of the human being and the whole of the environment was considered holistic. According to Rogers [5], when change no longer occurred, and the existence of pattern and organization ceased to exist, then death ensued. Rogers' theory of science of unitary beings allowed APNs to understand how the human being connected with the environment, to know how the human being evolved into a complex entity, and to comprehend how the human being was perceived.

\section{Attributes}

Within a concept, attributes must exist for the concept to be present. Walker and Avant [2] defined attributes as specific characteristics of a concept:"that is, they help you and others name the occurrence of a specific phenomenon as differentiated from another similar or related one" (p. 162).When considering the concept of energy pertaining to the APN, the attributes were as follows: (a) person, (b) aura, (c) movement, and (d) current.

The American Heritage New Dictionary of Cultural Literacy [12] defined person as "a human being, whether an adult or child" (para.1) and "an individual human being who likes or prefers something specified" (para. 3). Person related to philosophy was defined as "a self-conscious or rational being" (para. 5). A person was required for energy exchange between one field and another [5]; therefore, in the context of advanced practice nursing, the APN must be present for energy to occur.

The definition of Aura was as "an energy field that is held to emanate from a living being" [13]. The auras of APNs were always being emitted, either positively or negatively influencing themselves or their surroundings. Martin and Moraitis [14] defined aura as a vibratory essence surrounding all living things and considered the aura the blueprint of the soul. The energy exchanged through 
thoughts, conversation, and emotions. The APN's environment included patients, so the flow of energy directly impacted patient care. Martin and Moraitis [14] contended:

The most effective way to improve yourself, improve the world, and create your heart's desire is to develop yourself spiritually.Your spiritual growth is the key to drawing closer to God, fulfilling your purpose in life, and attaining true joy and satisfaction in all that you do. (para. 7).

\section{Encyclopedia Britannica [15]defined electric current as follows:}

Any movement of electric charge carriers, such as subatomic charged particles (e.g., electrons having negative charge, protons having positive charge), ions (atoms that have lost or gained one or more electrons), or holes (electron deficiencies that may be thought of as positive particles). (para. 1).

The electric current created magnetic fields where current flowed. APNs generated electrical current because the nurses were products of energy, and current flowed through the fields of APNs.

Movement defined by the Merriam-Webster Online Dictionary [16] was "the act or process of moving people or things from one place or position to another" (para. 1). Electrical currents conducted energy between one human being and another. The energy moved from the energy fields of APNs and patients. Without movement, energy exchange between fields was not possible.

\section{Antecedents and Consequences}

The next step in a concept analysis was identifying the antecedents and consequences of a concept. Walker and Avant [2] explained, "Antecedents are those events or incidents that must occur or be in place before the occurrence of the concept" (p. 167). Antecedents pertinent to the concept of energy were found to be God, or a higher power, and life. God or a higher power was essential to the concept of energy. Without God or a higher power, energy ceased to exist, and life ended.

Walker and Avant [2] defined consequences as "events or incidents that occur as a result of the occurrence of the concept" (p. 167).The consequences were the end-result of the concept. Consequences related to the concept of energy included:(a) healing, (b) transcendence, (c) spiritual tranquility, (d) trust, (e) attachment, (f) illness, and (g) death.

Nurses provided holistic care to their patients to promote comfort and healing. Nurses utilized a wide range of interventions, both physical and spiritual, to ensure care for all aspects of the human being. Kissinger and Kaczmarek [17] discussed the use of complementary and alternative medicine (CAM), specifically healing touch, to aid patients with fertility problems. Healing touch was a noninvasive energy-based therapy that allowed total healing of the human being. The healthcare provider manipulated the energy field of a human being to restore physical, mental, and spiritual balance. Kissinger and Kaczmarek [17] described their experience utilizing healing touch to help a woman become pregnant. The authors concluded healing touch promoted relaxation, confidence, and ultimately healing of the woman's disrupted energy fields. The philosophy of APNs has been the same as nurses regarding the provision of quality care, so APNs can encourage healing through their patient's energy.
Transcendence was another consequence of APNs who utilized or manipulated their energy when interacting with patients. Van Sell and Kalofissudis [3] identified transcendence as a result of the selfobservation methodology. Transcendence enabled the nurse to ask deeper questions related to the stability of a human being's nous, physical, and psyche level. The nurse obtained a greater understanding of the human being by extending beyond the space and time of a situation. Similarly, Davis [18] discussed engaging in activities beyond left-brained thinking, thereby enabling individuals to connect with a force within them. APNs who were capable of transcendental thinking gained a greater insight into themselves as well as their patients. In addition, APNs who were able to separate themselves from life's chaos evolved into their nursing practice.

Spiritual tranquility acquired through the APNs' use of energy. Spirituality enhanced the mental, physical, and emotional state of an individual [19]. Although spirituality was subjective, individuals who possessed spiritual tranquility knew their life's purpose and life's meaning. Spiritual tranquility enhanced individuals' relationships with others as well as relationships with themselves. Connectedness to God or a higher power also provided motivation, empowerment, and hope [19]. Spiritual tranquility provided the APN with confidence to make decisions regarding a patient's treatment plan. The ability of APNs to acquire spiritual tranquility also gave them the necessary tools to continue to practice and to remember why they became APNs in the first place.

Death was another consequence of the concept of energy. Van Sell and Kalofissudis [3] discussed in CINT how the human being ceased to exist when no interaction occurred with the environment. The human being comprised an open, complex system that continuously exchanged energy with the environment [3]. The exchange of energy enabled the system to be stable and evolve dynamically. When a human being reached equilibrium with the environment, the human being died. The cognition, development, and knowledge reached an end. APNs must continuously interact with their environment to maintain energy flow. The energy exchanged between the APN, and the environment encouraged the APN to learn, grow, and evolve his or her practice. When an APN no longer exchanged energy, the consequence of death ensued.

The positive exchange of energy encouraged attachment between the APN and the patient. The interaction of the APN's energy field and the patient's energy field formed a mutual relationship. Schodt [20] credited Rogers' science of unitary being for the development of attachment between energy fields. The study conducted by Schodt [20] focused on a father's attachment to his unborn child in utero through the use of energy fields. The expectant father's energy field was in constant interaction with the environment, which included his unborn child. The energy fields of the father and unborn child continuously changed.

\section{Model Case}

According to Walker and Avant [2], a model case comprised a pure instance of a concept. The following case study portrayed the concept of energy.

Channing was a 35-year-oldregistered nurse who practiced nursing for the last ten years. He currently worked in the intensive care unit (ICU) and was a member of the peer review committee, precepted new graduate interns, and was recognized by the chief nursing officer 
(CNO) for the outstanding patient care he provided and a positive work ethic. His coworkers claimed that Channing was a shining force on the unit.

Channing had a previous work history with depressed and troubled teens. He chose that line of work when beginning his nursing career because his mother passed away when Channing was 16 years-old, and he never knew his father. Channing chose a life of violence and mischief after his mother's passing. At the age of 19, a close friend of Channing's, who had both parents available and active in his life, invited him to the family's church. Unexpectedly, Channing found the church consoling and began to attend church regularly. With the love and support of his new friends in the church, Channing came to know the love of God. As a result, Channing turned his life around and pursued a career in nursing, hoping to help others who suffered similar experiences.

Channing, now working in the ICU, just received a 50 -year-old female patient who had suffered a massive myocardial infarction and died. The patient's son Kyle had arrived at the unit in a panic to find out the circumstances of his mother's passing. Kyle started screaming and exclaiming that the hospital was at fault. During this unfortunate circumstance, Channing had memories of himself and his own mother's passing. He empathized with Kyle because he had lived through a similar tragedy. Channing spoke to Kyle, told Kyle that he was sorry for Kyle's loss, and Channing would keep Kyle and his family in his prayers. Kyle quieted down and started to cry, explaining that his mother was a pastor for over 20 years and instilled the love of God into their family for as long as he could remember.

\section{Empirical Referents}

Empirical referents are described as "the means by which you can recognize or measure the defining characteristics or attributes" (p. 168) [3]. Empirical referents are not tools to measure the concept. The empirical referents identified for the conceptof maternal-newborn bonding are affectionate acts including hugging, kissing, skin-to-skin contact, and breastfeeding. A mother-to-infant bonding scale was designed to assess the mother's feelings towards her new baby. The scale consisted of 8 questions, and the mother should take it during the first three days after she delivers the baby [21].

The energy exchanged between Kyle and Channing was regarding a higher power. Unknowingly, both shared the same belief in a higher being. Channing was a person who was a product of God's energy. The current of positive energy passed to Kyle in his time of need. Channing was also known to be a positive force on the unit, which was a portrayal of his aura. Channing maintained constant movement of energy back and forth with Kyle.

\section{Borderline Case}

A borderline case contained most-or even all-of the defining characteristics of a concept but differed substantially from the concept [2]. The following was an example of a borderline case.

Allison was a 24-year-old registered nurse who practiced for a year. She currently worked on a busy labor and delivery unit that produced 250 deliveries a month. Allison was known to be frazzled in highstress situations, but she was well-liked among her coworkers. In the past, she had suffered from anxiety and poor adaptation skills from being in multiple foster homes as a child. Despite her history, Allison had received several compliments from former patients on her gentle nature and willingness to help.

Allison was assigned a laboring patient. The patient was37 weeks and four days gestation age and a gravida 6, para 4 with a history of an intrauterine fetal demise at 37 weeks gestation. The patient's cervical exam revealed she was 7 centimeters dilated, $80 \%$ effaced, and zero station. The patient was contracting every 2 minutes and declined an epidural. The patient anxiously notified Allison that she had suffered one loss and was worried about the baby coming fast. Allison was frustrated and frantically attempted to get the patient's admission orders done, an IV inserted, and the room set up for delivery. Allison gave the patient positive reinforcement, but the nurse did not address the patient's concerns.

The patient was now 10 centimeters dilated, $100 \%$ effaced, and +2 station. The patient notified Allison that she was pushing uncontrollably and did not want her baby born without a doctor present. Allison observed that the infant was crowning. Allison ran out into the hallway to see if anyone nearby could assist, leaving the patient and her husband alone. Allison's co-workers came to her aid only to find the baby had delivered in the bed. With moderate tactile stimulation and bulb suctioning, the baby cried vigorously, and the 1-minute Apgar score was 6, and the 5-minuteApgar assigned was 9.The patient informed Allison that she was scared when Allison ran out of the room. Allison told the patient that she had pushed like a champ.

Allison and the patient were individuals. Allison was a person. She and her patient were two different energy fields with constant energy exchange. The movement of energy was conveyed through the patient's constant emotional and physical changes as she progressed through labor under Allison's care. Although Allison maintained her professionalism, her inability to adapt to the situation may have blocked potential energy currents or flow during the care given.

\section{Contrary Case}

Walker and Avant [2] explained, "contrary cases are straightforward examples of what a concept is not and that it is often easier to say what something is not than what it is"(p. 166).The following exemplified a contrary case.

Reba was an acute care nurse practitioner (ACNP) working in a high-volume medical ICU. She received notification of a 21 -yearoldpatient who suffered from a self-inflicted gunshot wound to the head and was starting to decline. The patient remained full code status per his family's request. Thirty minutes later, a code blue was called on the patient. The ACNP was responsible for running the code blue. The code blue lasted for 30 minutes before the time of death was called. Maximum efforts were made to save the patient's life, but the result was death. Regarding the concept of energy, all sources/forms of energy ceased to exist when death occurred. A person no longer existed nor had anaura, movement, or current of energy flow in death.

\section{Empirical Referents}

Dolores Krieger [21], a nurse researcher, studied the power of therapeutic touch extensively. According to Krieger [21], "touch is probably one of the most primitive sensations" (p. 784).Touch spoke louder than words. One of the first sensations a newborn baby had was touch. From the moment the newborn entered the world, 
development transpired through tactile stimulation. Therapeutic touch was a simple intervention, but positively influenced an individual's well-being. Therapeutic touch required the practitioner or healer to place his or her hands on or close to the body of the sick person for 10-15 minutes.

Krieger [21] discussed the healer Oskar Esteban, who conducted several double-blind studies on the laying-on of hands in mice and barley seeds. The results of his study concluded therapeutic touch promoted healing and growth. Krieger followed the works of Esteban, conducted her research on therapeutic touch, and discovered that Eastern cultures had different views on the human and environment relationship. For instance, Eastern literature discussed prana, or vitality, and referred to an ill person as having a deficit of prana. The prana could be transferred person-to-person and was related to oxygen. Krieger conducted several studies on the influence of laying-on hands on the mean hemoglobin values of ill persons. One study used the nurses as healers in a hospital setting. The results of the studies indicated that therapeutic touch elevated the hemoglobin levels of the ill persons. Therapeutic touch had a profound impact on the energy and well-being of individuals. APNs can use therapeutic touch at any time during their practice.

\section{Impact of the Concept of Energy}

APNs used the concept of energy throughout their practice. Some nurses already established in their practice have become interconnected with their environments and their provider role. Building a nursing foundation and continuing to grow as a provider has led APNs to greater nursing knowledge. The authors of this analysis believed that energy came from a higher being; with that continuous energy, APNs adapt better to their surroundings and the clientele in their practice.

\section{Discussion}

Energy: A Concept Analysis Model, as shown in Figure 1, illustrates the concept analysis of energy from a visual perspective. The attributes regarding the concept of energy were: (a) person, (b) aura, (c) movement, and (d) current. The antecedents regarding the concept were: (a) God/Spiritual and (b) life. The consequences for the concept of energy emerged as healing, transcendence, spiritual tranquility, trust, attachment, illness, and death.By gaining a better knowledge base of the concept of energy, the APN can obtain a sense of self and value the interconnectedness of everyday practice.

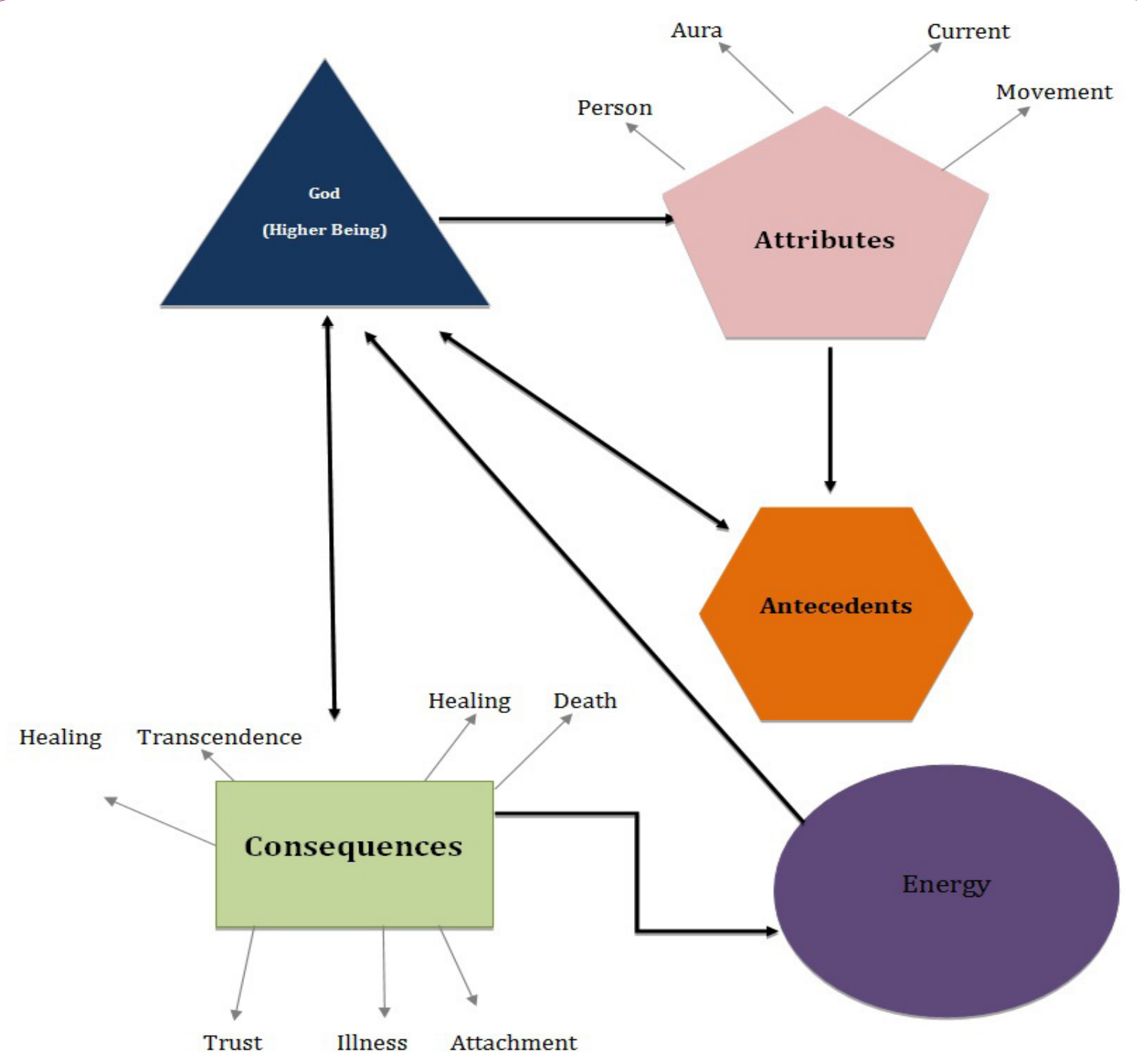

Figure 1: Energy: A Concept Analysis Model. 


\section{Competing Interests}

The authors declare that they have no competing interests.

\section{Funding}

This article was published with support from Texas Woman's University Libraries' Open Access Fund.

\section{References}

1. Todaro-Franceschi $V(2001)$ Further reflections on energy fields. Nursing Science Quarterly 14: 182-186.

2. Walker LO \& Avant KC (2011) Strategies for Theory Construction in Nursing (5th ed.). Upper Saddle River, NJ: Prentice Hall.

3. Van Sell SL, Kalofissudis IA (2002) The evolving essence of the science of nursing: Complexity integration nursing theory. (E-book), Athens, Greece: ICU Web Journal.

4. Levine ME (1967) The Four Conservation Principles of Nursing. Nurs Forum 6: 45-59.

5. Rogers ME (1970) An Introduction to the Theoretical Basis of Nursing Philadelphia, PA: F. A. Davis.

6. Energy (2016) In Merriam-Webster online dictionary.

7. Energy (2016) In Dictionary.com.

8. Energy (2016) In Cambridge Dictionary.

9. Energy (2016) In Business Dictionary.

10. Newton I (1850) In N. W. Chittenden \& A. Motte (Eds.), Newton's Principia The Mathematical principles of natural philosophy. New York, NY: Putnam.

11. Einstein A, Infeld L (1966) The Evolution of Physics From Early Concepts to Relativity and Quanta. New York, NY: Simon and Schuster.

12. Person (2016) The American Heritage ${ }^{\circledR}$ new dictionary of cultural literacy (3rd edition).

13. Aura (2015) In Merriam-Webster online dictionary.

14. Martin BY, Moraitis D (2016) The inner aura and your spiritual potential. Spiritual Arts Institute.

15. Electric current (2016) In Encyclopedia Britannica.

16. Movement (2016) In Merriam-Webster online dictionary.

17. Kissinger J, Kaczmarek $L$ (2006) Healing touch and fertility: A case report. J Perinat Educ 15: 13-20.

18. Davis CM (2003) Empathy and transcendence. Topics in Geriatric Rehabilitation 19: 265-274.

19. Coyle J (2002) Spirituality and health: Towards a framework for exploring the relationship between spirituality and health. J Adv Nurs 37: 589-597.

20. Schodt CM (1989) Parental-fetal attachment and couvade: A study of patterns of human environment integrality. Nurs Sci Q 2: 88-97.

21. Krieger $D$ (1975) Therapeutic touch: The imprimatur of nursing. American Journal of Nursing 75: 784-787. 